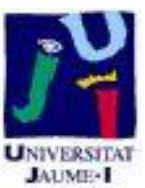

Título artículo / Títol article: Participative site-specific agriculture analysis for smallholders

Autores / Autors

Pau Aragó Galindo

Carlos Granell

Paulo Guilherme Molin

Joaquín Huerta Guijarro

Revista:

Precision Agric (2012) 13:594-610

Versión / Versió:

Post-print

Cita bibliográfica / Cita bibliogràfica (ISO 690):
ARAGÓ GALINDO, Pau, GRANELL, Carlos, MOLIN, Paulo Guilherme, HUERTA GUIJARRO, Joaquín. Participative site-specific agriculture analysis for smallholders. Precision Agriculture, 2012, No 13, p. 594-610. 
Short form of author list

\title{
Participative site-specific agriculture analysis for smallholders
}

\author{
Pau Aragó Galindo ${ }^{1}$. Carlos Granell ${ }^{1}$. \\ Paulo Guilherme Molin ${ }^{2}$ · Joaquín Huerta Guijarro ${ }^{1}$
}

Received: date / Accepted: date

\begin{abstract}
Site-specific agriculture has been adopted in a high-tech context using for instance, in-situ sensors, satellite images for remote sensing analysis, and some other technological devices. However, farmers and smallholders without the economic resources and required knowledge to use and to access the latest technology seem to be an impediment to precision agricultural practices. This article discusses the possibility of adopting precision agriculture principles for site-specific management but in a low technology context for farmers. The proposed methodology to support precision agriculture combines low technology dependency and a participatory approach by involving smallholders, farmers and experts. The proposed use-cases demonstrate how the interplay of low technology and participative dimensions may be suitable to smallholders for site-specific agriculture analysis.
\end{abstract}

Key words:site-specific $\cdot$ low technology $\cdot$ GIS $\cdot$ smallholders $\cdot$ participatory GIS

\section{Introduction}

Site-specific agriculture can be defined as a method for managing soil and crop production in a spatial and precise manner. It takes into account the conditions of various areas that, when combined, define the farming land (Schueller 1992). Site-specific agriculture is sometimes associated with the need of high technological equipment such as sensorenabled devices, Global Positioning Systems (GPS), and Geographical Information Systems (GIS). Technology providers and developers are pushing stakeholders to continuously adopt the latest technologies (Lamb et al. 2008). Nevertheless, precision agriculture (PA) should not be understood as a high-tech discipline by definition (Molin 1997), that has its roots in an 'observe-interpret-evaluate-implementation' methodology regardless of the means and tools used (Cook and Bramley 1998). Furthermore, a low technology approach should also be suitable for site-specific analysis provided that the driving principles behind the 'observe-interpret-evaluate-implementation' methodology are supported (Bouma et al 1999).

PA became an attractive idea for most farmers and agriculture experts in developed countries as a method for optimizing agricultural production (Roberts et al. 2004; Sassenrath et al. 2008; Cook et al. 2003). For instance site-specific agriculture became attractive for delineating productive zones base on soil quality and production (Mann et al. 2011). Indeed, many smallholders already have the idea of site-specific management in

\footnotetext{
${ }^{1}$ F.T.F. Author

Av. de Vicent Sos Baynat, s/n 12071 Castelló de la Plana, Spain

Tel.: +34-964729058

E-mail: p.arago@uji.es, huerta@uji.es, canut@uji.es

${ }^{2}$ S. Author

"Luiz de Queiroz" College of Agriculture, University of São Paulo, São Paulo, Brasil
} 
their minds (Cook et al. 2003), even if it is in their subconscious. An example of this is when a limited quantity of fertilizer has to be applied to only a specific location where and when it is needed and not evenly spread across all the farmland (Stoorvogel 2006). Other research has found that farmers know their farm's features and variability (Booltink et al 2001). Nevertheless, a couple of limiting factors seem to impede the exploitation of PA by smallholders for site-specific analysis in small farms.

First, PA has been based mostly on information technology, high levels of machinery and computation knowledge. This refers to an increase in economic resources as 'input'. For example, the application of high positional accuracy involves implementation costs (Booltink et al 2001) and training time. This issue affects developing and developed countries alike, since in developed countries the use of the latest technology in PA is not as widespread as believed (Lamb et al. 2008). Indeed, in Southern Europe the use of sitespecific agriculture 'has been delayed because of small farm size' (Fountas et al. 2010) among other reasons. Moreover, in developing countries a good portion of the population has a lack of expertise and access to the 'digital world' that surrounds many others; it has been called the digital division between developed and developing countries (ITU 2010). This situation is worse in rural areas which have less access to information technology, as compared to urban areas (James 2008). This gap is filled mostly but not always by 'leading farmers' who are often more highly educated, or take a local/regional 'leadership role' (Lamb et al 2008) as early adopters of PA technology.

Second, PA is more feasible when the farmland is larger or based on the educational level of the owner (Roberts et al. 2004). Nevertheless, smallholders know their land. They know which areas are the best and they can estimate their crop yield according to their observations. The problem is that this appreciation and knowledge is not recorded and shared. In contrast, experts have both academic and technical know-how. Experts advise smallholders based on their know-how and on information provided by smallholders. This information exchange among experts and conducted through oral communication.

What are the effects of these two factors on site-specific agriculture? Site-specific concepts remain the same, regardless of the farm size and the farmer's educational level. Our assumption here is that farmer's knowledge on their land is of critical value compared with technological equipment and the application of sophisticated procedures, which are not needed but of added value (Aggelopoulou et al. 2009). Computational resources, training, and even education are scarce in rural environments (Diagne 2009). Even without the potential of being able to use high level technology, small farmers are still able to apply site-specific concepts and ideas by just referring, for instance, to paper maps. This is possible because small farmland owners are more familiar with their own land (Altieri 2004). Since most smallholders are traditional families that have lived on the land for quite some time, they can utilize their 'mental maps' to manage their land (Cook et al 2003). However, it is important to provide farmers with environmental and agricultural education by using a methodology that will allow them to make appropriate decisions (Ma et al 2009).

The problem raised here is how to communicate the concepts of PA for site-specific management strategies to smallholders in those cases where it is potentially feasible without having to use a high level of technology. This particular aim was to find out if monitoring, analysis, and information exchange of farm production and management, following site-specific agricultural principles would be feasible with low technology dependency for farmers in participatory contexts.

The paper focused on the use of a site-specific methodology and techniques for smallholders. The proposed methodology used as much of the available concepts of PA for site-specific agricultures as possible without having to use new technologies unknow to the smallholders. In addition, a co-operation among smallholders and experts is promoted to 
exchange information and advice. The methodology developed might be applied to smallholders in developed and developing countries.

\section{Materials and methods}

\section{Study Area}

The study compromise five different small fields (parcels) located in La Vall d'Uixó, Valencian Community (Spain). Fig 1 shows the location of the parcels. The orange cultivation in the Valencian Community has been traditionally performed on terraces. A terrace has similar characteristics of soil and tree variety. The terraces were originally built to irrigate the trees using border irrigation techniques as well as to avoid erosion problems. A given field or parcel groups various terraces, since the tasks performed in the field are planned on the basis of the natural division into terraces with theoretically homogeneous conditions.

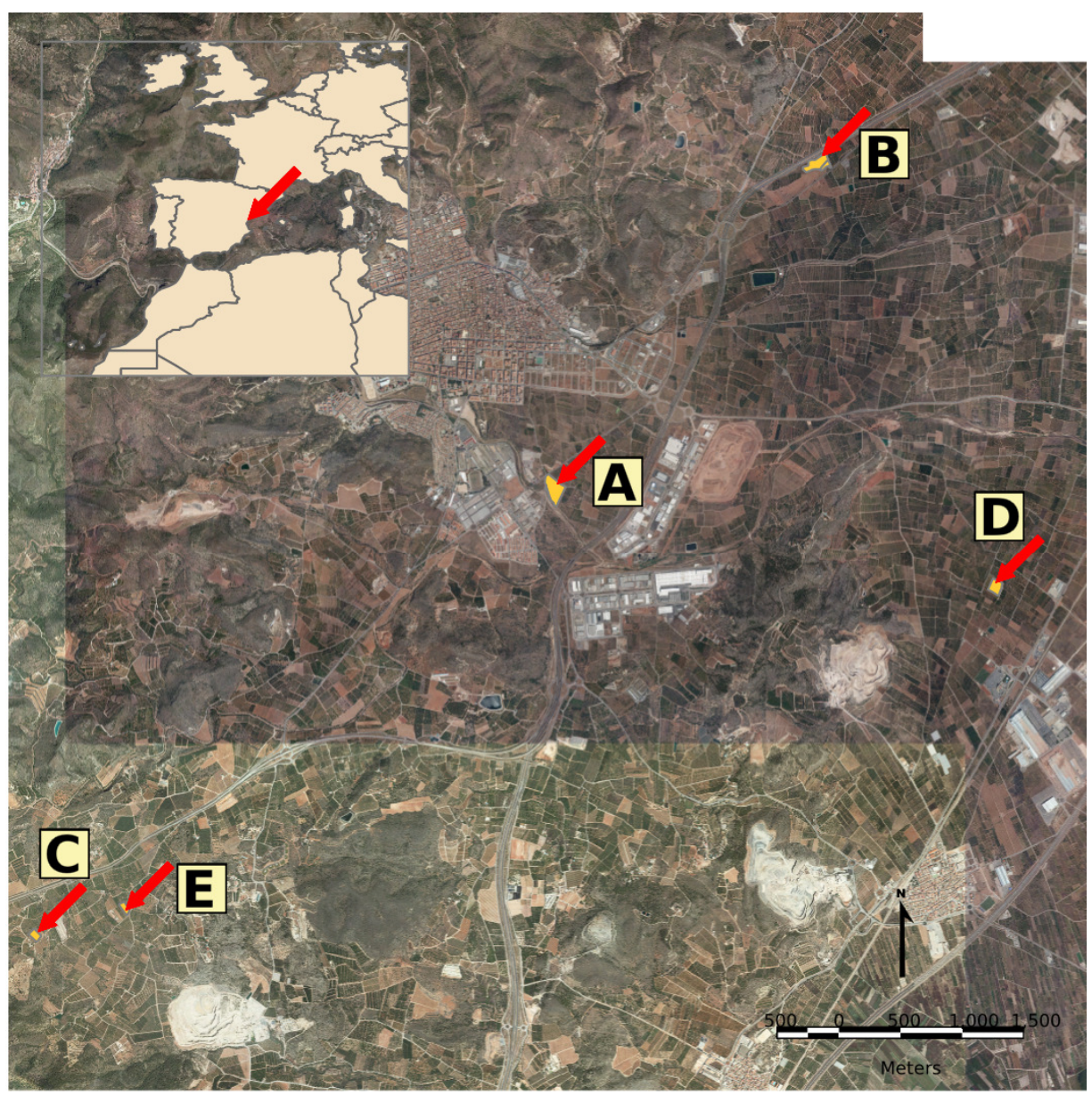

Figure 1: Location of the farms at Vall d'uixo Municipality. Red arrows mark the location of the parcels in orange color.

Table 1 shows the details of the fields studied. The field selected as a reference example throughout this paper ('A' in Table 1) is a single field with an area around 2.71 ha, Fig 2, with only one owner. The farmers A, C, D and E are part-time farmers, while the farmer B is a fulltime farmer. All the fields are cultivated with orange trees based on drop irrigation systems. The orange tree variety is mostly Clemenules. In the case of farm A, 11 terraces 
are devoted to Clemenules, and only one terrace to Hernandina, terrace labeled as m5 (Fig 2). All the fields were transformed from an olive and/or carob tree cultivation to the present orange trees between 1935 and 1990. With this change, a new layer of soil was laid in the area to improve soil conditions for the new cultivation. New soil was provided by tracks increasing the soil depth and leveling the field. The terrace may vary depending on the original terrain slope, being more narrow higher the slope.

\begin{tabular}{|c|c|c|c|c|c|c|}
\hline $\begin{array}{l}\text { Parcel/ } \\
\text { Farmer } \\
\text { id }\end{array}$ & $\begin{array}{l}\text { Parcel } \\
\text { Area } \\
\text { (ha) }\end{array}$ & $\begin{array}{l}\text { Number } \\
\text { terraces }\end{array}$ & $\begin{array}{l}\text { Average } \\
\text { terrace area } \\
\left(\mathrm{m}^{2}\right)\end{array}$ & Orange tree & $\begin{array}{l}\begin{array}{l}\text { Orage field } \\
\text { since }\end{array} \\
\end{array}$ & Coordinates \\
\hline A & 2.71 & 12 & 1951 & $\begin{array}{l}\text { Clemenules } \\
\text { hernandina }\end{array}$ & $1951-1968$ & $39^{\circ} 48^{\prime} 43.37^{\prime \prime} \mathrm{N} \quad 0^{\circ} 13 \prime 21.08^{\prime \prime} \mathrm{O}$ \\
\hline $\mathrm{B}$ & 1.7448 & 4 & 4362 & Clemenules & $1935-1960$ & $39^{\circ} 50^{\prime} 06.93^{\prime \prime} \mathrm{N} \quad 0^{\circ} 11^{\prime} 47,260$ \\
\hline $\mathrm{C}$ & 0.5409 & 3 & 1803 & Clemenules & $1983-1990$ & $39^{\circ} 46^{\prime} 50.64^{\prime \prime} \mathrm{N} \quad 0^{\circ} 16^{\prime} 22.22^{\prime \prime} \mathrm{O}$ \\
\hline D & 0.9917 & 3 & 3306 & Clemenules & $1958-1962$ & $39^{\circ} 48^{\prime} 13.96 " \mathrm{~N} \quad 0^{\circ} 10^{\prime} 52.06^{\prime \prime O}$ \\
\hline E & 0.4495 & 1 & 1498 & Clemenules & 1970 & $39^{\circ} 46^{\prime} 57.00^{\prime \prime} \mathrm{N} \quad 0^{\circ} 15^{\prime} 51.56^{\prime \prime} \mathrm{O}$ \\
\hline
\end{tabular}

Table 1: Description of the farms of the study.

Farm A is representative of the Valencian Community's most common orange orchard farm. In the Valencian Community, $3 \mathrm{ha}$ is the average size of an orange farm (M.A.P.A 2003). $78 \%$ of farmers are part-time farmers (M.A.P.A 2003). 


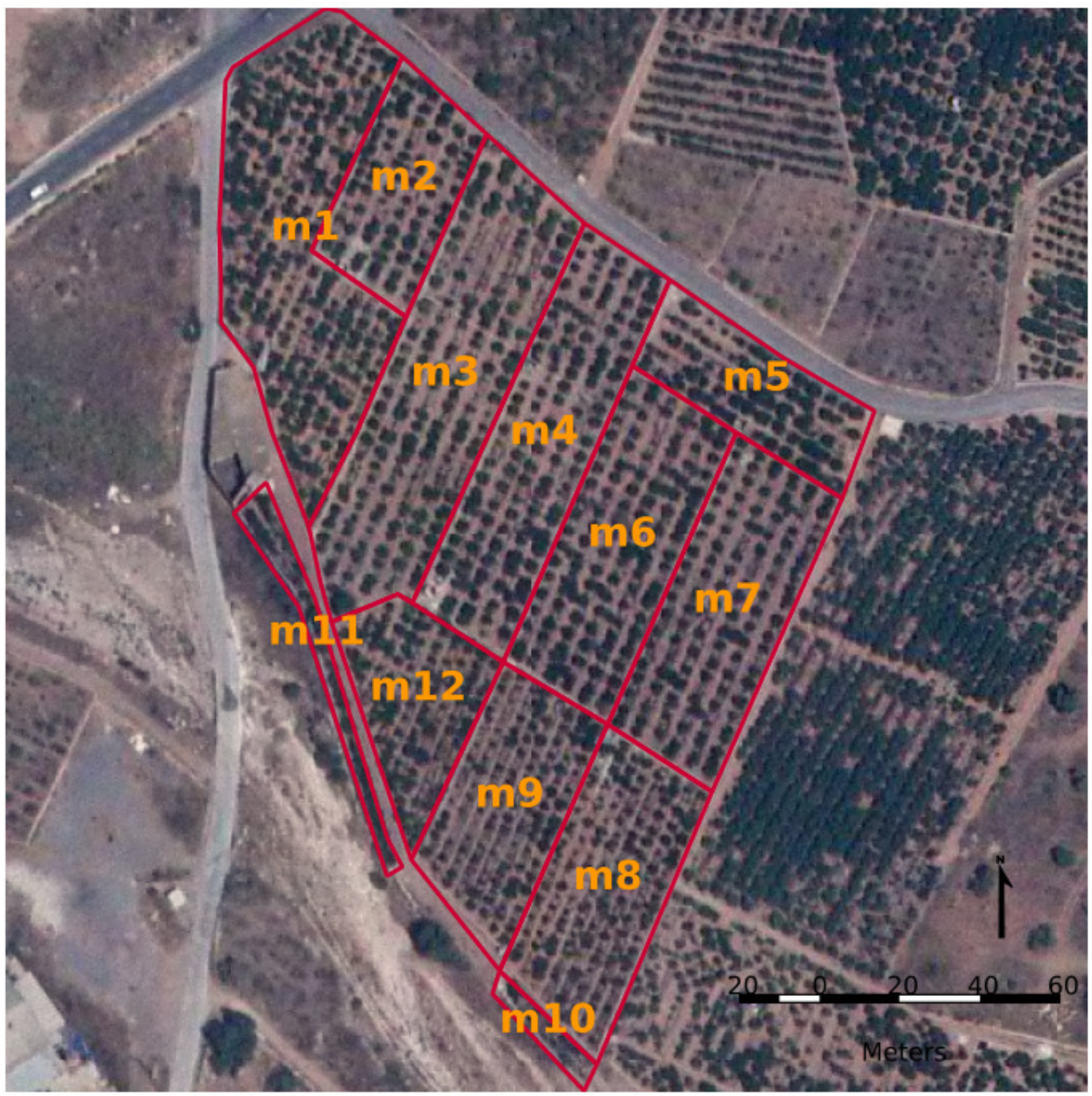

Figure 2: Aerial image of the field 'A'. Terraces are marked with red lines.

\section{Methodology}

The proposed methodology aims to collect and exchange spatial data to support sitespecific analysis and decision-making based on two dimensions: low technology dependency for farmers and participatory context. The former refers to minimize the use of technology to obtain the same or similar results. Many authors have proposed the use of GIS tools and geospatial services to benefit from software open source tools and online spatial data available (i.e, Nash et al. 2009; Paar and Rekittke 2011). In this paper, however, the term low-technology dependency suggests the use of traditional means in those contexts where high-technology tools and devices are limited (lack of resources, knowledge, time, etc.) or when a site-specific analysis can be carried out without the introduction of high level technology.

The latter, the participatory dimension, refers to a bottom-up approach to share information between participating stakeholders. In the geospatial information community, data collection is moving from a top-down approach to a bottom-up approach (Budhathoki et al. 2008). A top-down approach is a traditional way of collecting data by official 
institutions and experts. A bottom-up approach means that ordinary people are working as voluntary 'sensors' (Goodchild 2007). People can be like sensors providing spatial information directly from a source. In this scenario, experts can collect spatial information but can also take advantage of an individual's (such as a farmer/smallholder) contribution as a voluntary 'sensor'. The farmer's individual contribution is part of a wider contribution collected by the expert. This way of collecting spatial information has been called participatory GIS (PGIS) by Sieber (2006). PGIS facilitates data sharing and knowledge and learning interchange between involved participants (e.g. Hall et al. 2010; Bugs et al. 2010).

For this research, the principles of precision agriculture for site-specific management (Srinivasan 2006) will be applied to 5 small orange tree farmlands in Spain (Table 1). The farmer will collect spatial data using paper maps and notes. This data will be shared with an expert, who then uploads it into a GIS application. The expert can then perform data analysis to provide feedback to the farmer in a personalized way. In this way, farmers can acquire information in a short time frame by observing the environmental resources and production, consequently learning how to improve the management of their land. For example, farmers tend to know which part of the land might be better than another part by simply observing the crop's progression. These observations are in fact low technology site-specific information that can and should be applied.

Furthermore, two kinds of participants are involved in the following use cases with different technological experience. The first, the expert, will use GIS technologies (hightech use case) that are not always accessible to smallholders. The second will use only paper and pencil (low-tech use case) while still implementing site-specific agriculture behind the principles of PA.

High-tech use case

This section describes the use-case steps followed by the farmer and the expert user to collect needed data, upload it into a GIS tool to perform site-specific analysis ( Fig. 3). 


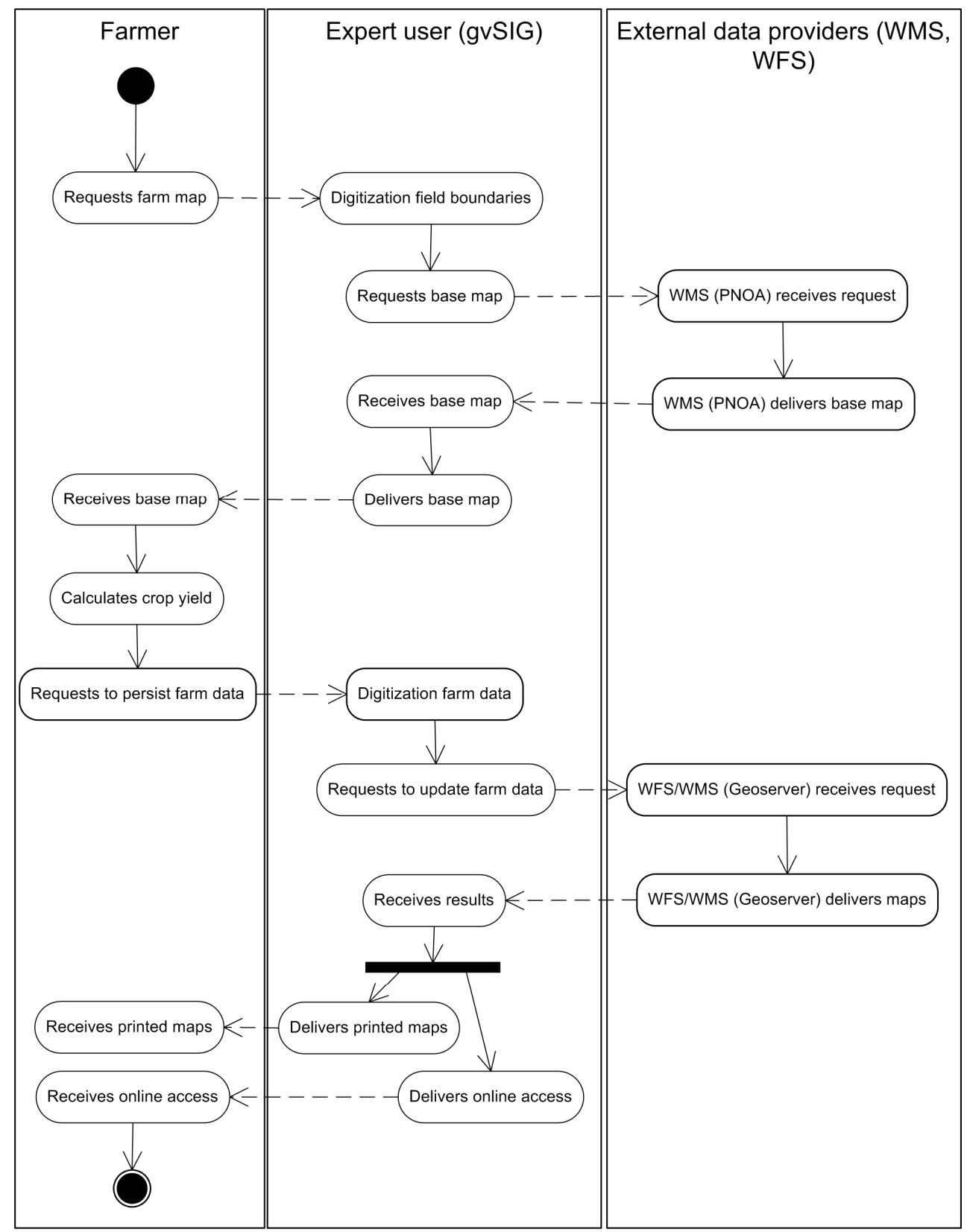

Figure 3: UML activity diagram for the high-tech use case

The first step is data preparation. It consists in this case of digitizing the field boundaries, terraces and trees (Fig. 4). The most important issue in site-specific is location. The location is needed to assign inputs and outputs, in order to perform a posterior analysis, focused on the results per terrace. In other words, site-specific management cannot be performed without spatial data (i.e., data is associated to a concrete location). The map of the field must be drawn for this task. The technology used was gvSIG ${ }^{3}$ tool that allowed the expert user to access to remote spatial data sets such as aerial imagery of the study area from the $\mathrm{PNOA}^{4}$ server and thematic layers provided by the national cadastral

\footnotetext{
${ }^{3}$ gvGIS is an open source GIS client tool to manage local and remote geospatial data sets (http://www.gvsig.org/web)

${ }^{4}$ Spanish national project that manages and offers orthophoto coverage created from aerial photography (http://www.ign.es/PNOA/)
} 
agency $^{5}$ servers. Hence, the subdivision of the field of study is going to be digitized according to the terrace distribution (Fig. 2). It is also the same division used for the farmer's handmade map. The use of the PNOA image allows for the digitization of the tree's position. The expert user provides a paper map of the farm with the terraces division (Fig. 4), cadastral agency data and tree position.

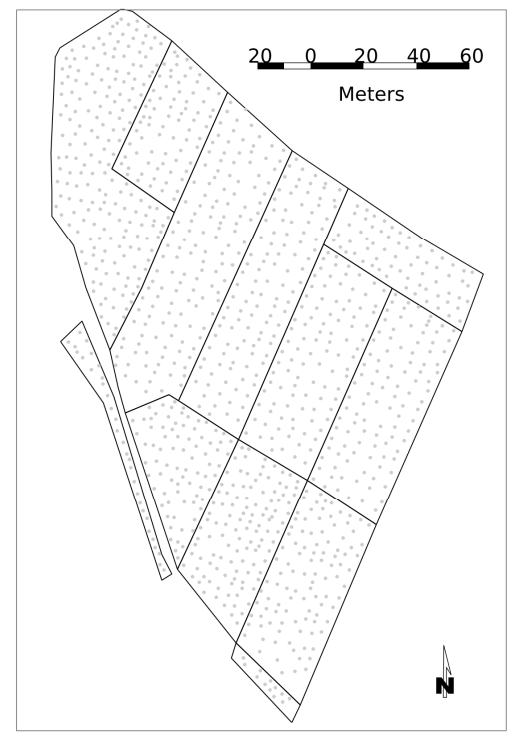

Figure 4. Field map provided to farmer A by the expert. The map shows the division in terraces of the parcel and the tree location.

The second step is concerned with data collection. The data collection is going to be done exclusively by the farmer. In the case of smallholders, it is sometimes difficult to discriminate outputs from each of the terraces within a parcel. Therefore, an effort has been made to measure the crop yield for each terrace (i.e., each subdivision in Fig 2). The crop yield was harvested manually. Two farmers have measured the crop yield harvested by terrace (parcels A and C), and two farmers have measured the crop yield by parcel (parcels B and D). Farmers B and D do not known which amount of crop yield correspond to which terrace. The parcel D has only one terrace within the parcel. On the other hand, the orange data quality is measured by the Orange Packing Co-operative, where the fruit is processed. The co-operative provides feedback to the farmer with a report of the orange yield quality of the farm, not per terrace. The farmer estimates the orange quality per terrace according to his experience. Hence, parcel orange quality is not considered in this paper because it is only estimation.

The third step consists of the expert translating collected farm data into a GIS tool, in this case gvSIG. Data is stored in a PostGIS ${ }^{6}$ database using gvSIG as a client application. Both, gvSIG and PostGIS, are available in several languages, such as open source which have on-line documentation and tutorials. gvSIG has a mailing list to help users. Data analysis in this case is based only on the computation of some crop yield production parameters, such as harvested oranges in $\mathrm{kg} / \mathrm{ha}, \mathrm{kg} / \mathrm{tree}$ and difference between years.

The fourth step refers to information feedback, which may be provided to the farmer using printed maps or via on-line map servers to which the farmer could connect to by

\footnotetext{
${ }_{6}^{5}$ National cadastral agency in Spain (http://www.sedecatastro.gob.es/)

${ }^{6}$ PostGIS is a spatial database extension for the open source PostgreSQL database

(http://postgis.refractions.net/)
} 
using a viewer application. Geoserver ${ }^{7}$ was chosen to provide on-line spatial feedback to the farmer. Fig. 5 shows the spatial information work-flow. Paper maps produced by the farmer can be available as historical records in Geo-TIFF ${ }^{8}$ format.

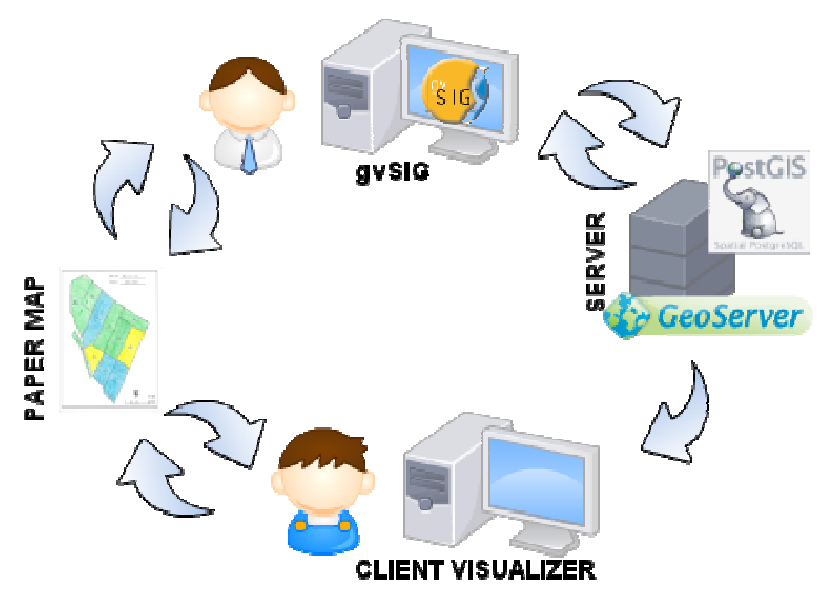

Figure 5: Spatial information work-flow

Low-tech use case

In a non-technology approach, the farmer must use the site-specific management tools and principles (Srinivasan 2006) without the implementation of high levels of GIS technology.

The first step is the data preparation regarding field boundaries and terraces. The farmers A, B, C, and D have (prior to the experiement) a sketched map of their land divided into terraces for managing reasons. All the farmers have been provided with a set of blank maps created with the gvSIG tool. All terraces have been measured and labeled according to their area and terrace number. The farmer is also provided with a map (Fig. 4) of the land describing the tree positions.

The second step is data collection. The orange tree production is provided by the owner of the field as is explained in the previous section. Spatial data is collected using paper maps and paper spreadsheets. There is no difference in the data acquisition adquierd by the expert user nor the farmer user. The farmers of parcels A and B show its fruit yield in the map in $\mathrm{kg} / 1000 \mathrm{~m}^{2}$ to be more easily interpreted by the farmer. The farmers of parcels $\mathrm{C}$, $\mathrm{D}$, and $\mathrm{E}$ have not a production map, so they do not know which crop yield corresponds to each terrace. A colored classification labeling system will be created by each farmer for the orange production, each farmer uses his own scale to represent the production in $\mathrm{kg} / 1000 \mathrm{~m}^{2}$. The farmers, according to the crop yield outputs, will color each terrace within the parcel. The result is a map with production information and easy to view colored classification. Each production year map will be stored as a hard-copy document to be used in the following years as a guide to fill in the information in the same way. The farmers also use the tree location map (Fig. 4) to mark those trees that are receiving special care or are under special control. Tree data is freely recorded by the farmer with just one condition: this recording must be clear for the expert user. A third map is created by the farmer to limit the areas of the field with different features regarding trees aspect or soil quality appreciation.

\footnotetext{
${ }^{7}$ Geoserver is an open source server to share and manage geospatial data. It is the reference implementation for some relevant OGC standards such as WMS and WFS (http://geoserver.org)

${ }^{8} \mathrm{GeoTIFF}$ is a file format for georeferenced raster imagery (http://trac.osgeo.org/geotiff/)
} 
The owner will be able to modify the inputs or perform special care according to the analysis of the paper maps and the expert's feedback. For example, terraces with good productivity in the last years will receive less or no input, whereas less productive areas should receive more input or special care. An alternative strategy would be to remove trees from less productive areas.

\section{Results and discussion}

According to the steps described in the Methodology, the results for the high-tech and lowtech use cases are described in the following sections.

High-tech use case

The use of GIS tools is an advantage because these tools allow the expert user to implement faster computation processes and advanced analysis using spatial data from remote information sources (i.e. PNOA WMS). In addition, gvSIG also allows to personalize (e.g., changes of colors, legends) and visualize the analysis results in a more interactive way. Furthermore, computations between the field records can be made. The $\mathrm{kg} /$ tree ratio has been calculated with gvSIG by the expert user. The computations in this case are simple. The tasks performed with gvSIG suport are:

- Calculation of Surface in $\mathrm{m}^{2}$, this surface is the same used for the farmer for his maps.

- Calculation of the production ration in $\mathrm{kg} / \mathrm{tree}$ and $\mathrm{kg} / \mathrm{ha}$. The ratio allows for direct comparison between terraces and parcels.

- Uploading tree information into the system according to farmer paper maps.

- Uploading spatial data into Geoserver.

- Uploading paper maps into Geoserver.

Fig. 6 shows output maps from gvSIG. The farmer receives the gvSIG output maps from the expert. The farmer can also retrieve spatial information from the Geoserver using a light client visualizer, Fig. 5.
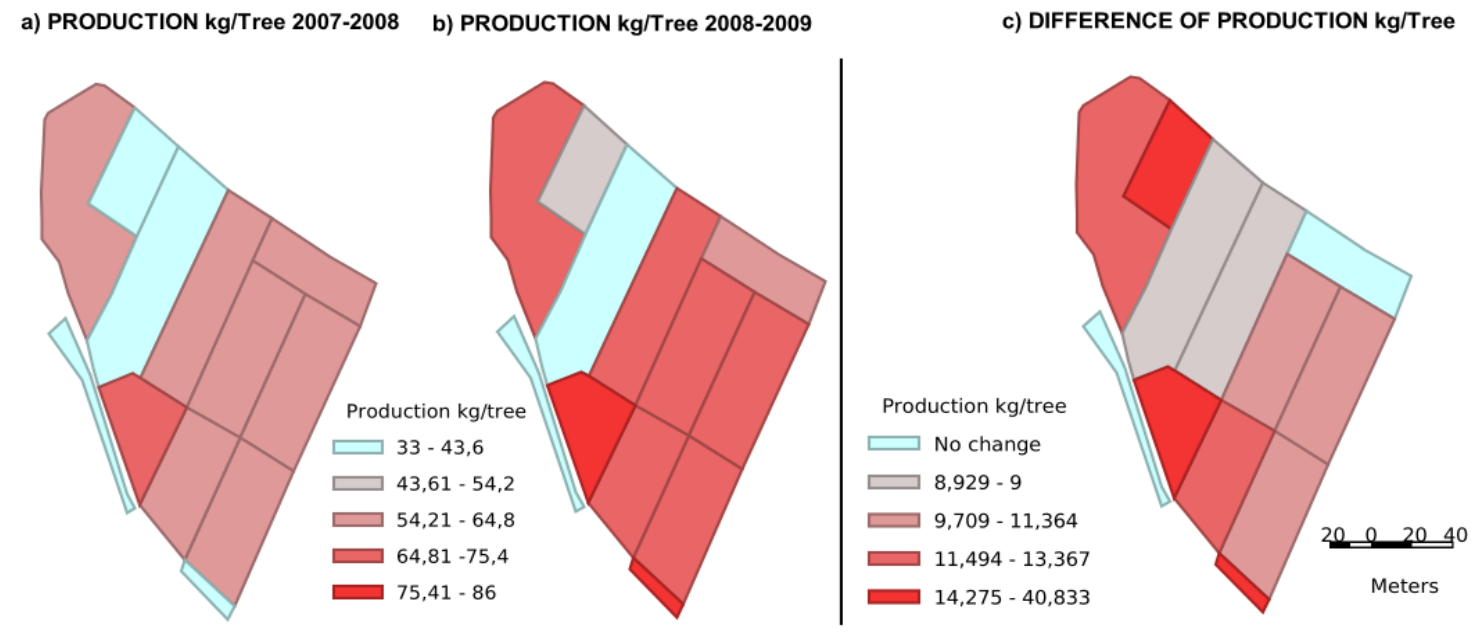

Figure 6: GVSIG output maps of the crop yiel distributed in terraces for parcel A. Seasons 2007-2008 and 2008-2009. 
Low-tech use case

Farmer A used paper maps to graphically describe the production of the parcel Fig. 7, also marked trees to limit areas of the field with similar features. The farmer drew the production to create the map using a quantitative scale, but also performed fast mental calculations to estimate the production maps regarding the yield. Some reasons motivated this. First the farmer thought it would be better to compare the production between terraces. Second, it would be better to have the production in $\mathrm{kg} /$ trees, because there are parcels that have some young, old or sick trees that are not producing oranges. These observations made by the farmer have been taken into account by the expert to produce a map with the location of the trees and to compute the $\mathrm{kg} /$ tree ratio. Paper maps with tree locations were used by the farmer in successive seasons to record qualitative information about the trees, such as old trees, new plant trees, non-productive trees, and special care (fertilizer addition) trees. The first orange production paper maps motivated the owner of parcel A to draw a map with his own observations about the soil quality. The other farmers, taking into account the experiences of parcel A were suggested to draw a map of soil quality. The different colored sections (i.e. Fig. 7) within the parcel were drawn according to farmer knowledge of the soil difference and visual apearence of the trees.

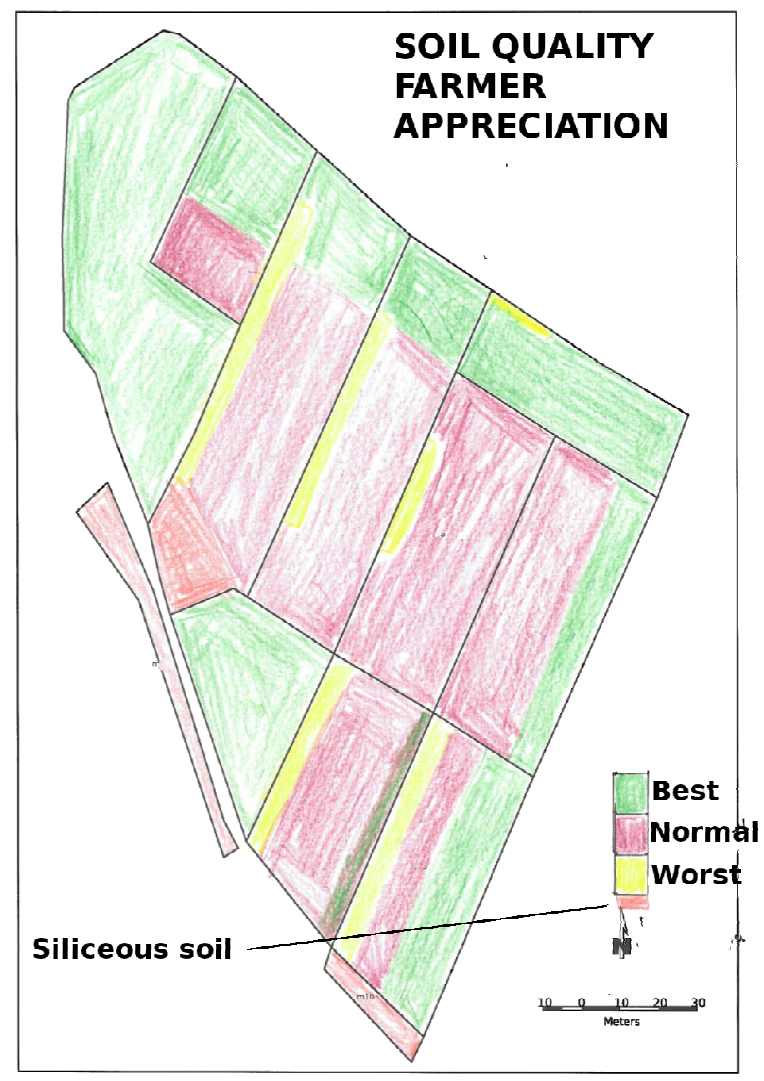

Figure 7: Colored map of soil quality appreciation by farmer A.

The time used by the farmers to record the information on maps (i.e. Fig. 7 and 8) and spreadsheets was around $4 \mathrm{~h}$ for farmer $\mathrm{A}$ and $1 \mathrm{~h}$ for farmers B, C, D, and E, given that all 
the data was previously collected and distributed per terrace or parcel. Finally, the data collected by the farmers was the following:

- Production for seasons 2007-2008 to 2010-2011 farmer A. seasson 2009-2010 and 2010-2011 for farmers B, C, D, and E.

- New plant trees (2007-2011), farmer A

- Old trees 2011, farmer A and B.

- Trees with extra special fertilizer (2009-2010). Farmer A, B, and C.

- Qualitative observation of soil quality and or tree apparence. 

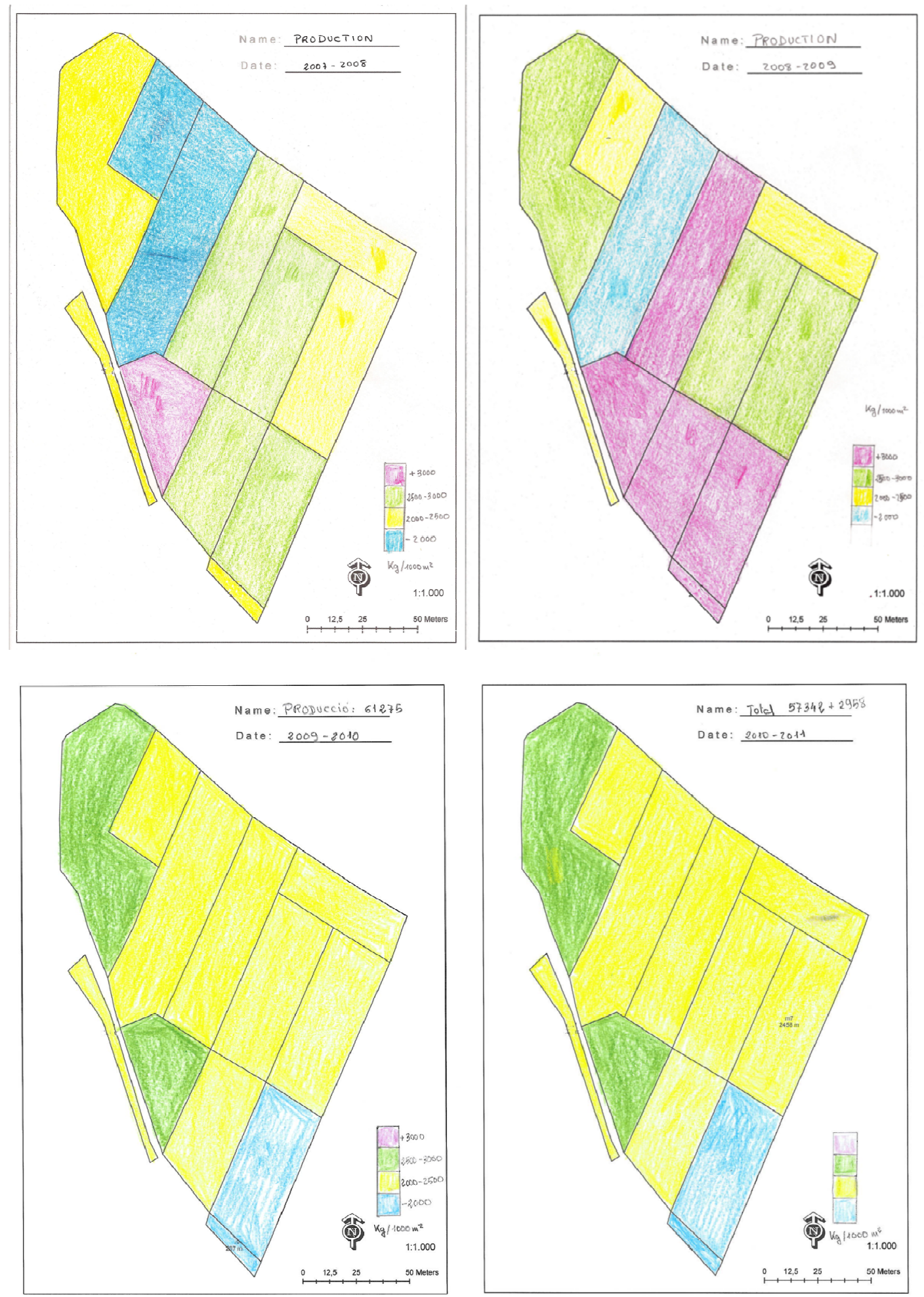

Figure 8: Colored map of the production distribution in the terraces of parcel A. Seasons 2007-2008 to 2010-2011.

\section{Technology dependency analysis}

The farmers like using handmade maps, as they are easy for them to create. The farmers can use these maps to follow the increase or decrease in production. The difference in the 
production maps (Fig. 8) clearly shows the terraces that have increased in production, and those that have maintained the same level of production (parcels A and C). Consequently, action plans will be defined according to the results of each parcel. Farmer A suggested an improvement for future maps by adding orange quality by visual appreciation, which has a relationship with the final price. Nevertheless, the orange's quality (feedback provided by the Orange Packing Co-operative) refers to the total amount of the farm's production, as was explained earlier. Farmer A also suggested to predict the yield by using tree flowering (Aggelopoulou et al 2009) enhanced with visual appreciation and then comparing it with the real production. All these new estimations and recordings would be done by the farmer using the handmade maps. The farmers $\mathrm{B}$ and $\mathrm{C}$ also wanted to continue making handmade maps. Indeed, they asked for more copies of their parcel maps to continue recording the results. Farmers A, B, C, and D concluded that it would be interesting to record the resulting maps to have an historical perspective of the evolution of their farms.

In general, the use of GIS tools or handmade maps had no significant difference from the farmers' point of view. The farmers easily performed hand calculations of the ratios and drew them on the maps. Nevertheless, if the farmer provides the amount of production to the expert, he can receive feedback of production's result in $\mathrm{kg} / \mathrm{tree}$. The difference for the farmer is the GIS output visualization.

Farmers have stated that they will not attend a basic course of now to use GIS tools for producing the maps, but they will continue with the methodology of using handmade maps ,for instance farmers $\mathrm{A}$ and $\mathrm{C}$ would record more parameters of the field inputs and outputs, such as the field's quality. Using this data they would produce some maps, plan their tasks and in some cases show the data and paper maps to a consultant expert. Only farmer E has no interest in follow up with paper maps, since his parcel is small and it has not so much economical profit.

Farmers A and C preferred the maps created with GIS tools, as they can the difference better with these maps than with handmade ones. They can easily visualize more information in different ways. Farmer A has noticed the evolution of terrace $\mathrm{m} 12$ where he has added fertilizer, because the trees had symptoms of a low level of iron (this is an observation of the farmer). The production has increased in this terrace. The expert provide feedback with GIS maps and provides a visual description of the situation.

Participatory GIS analysis

The farmer contributes to the process by providing data from his farmland. The expert user gets data from the farmer and uploads it to the GIS making the data available for other users. Expert users can provide spatial feedback to the farmer with processed information or with other spatial information that is considered important for the farmer, such as NDVI (Mann et al. 2011). This methodology will provide a dialogue between the farmer and the expert with a never ending work-flow of information (Fig. 5). All the farmers have concluded that are favorable to provide maps to expert. They also are favorable to share their data if an expert require it, only if they receive feedback and expert's advice.

This is a collaborative approach to data collection directly from the source, the farmer. With this data the expert can complete his/her spatial information with a wider overview of the situation and the farmer's concerns.

Site-specific implications

The result of this methodology will be a continuous collaboration among the different participants. The participants will interchange information. On one hand, the expert user does not know the field as well as the smallholders. On the other hand, the farmers require some advice regarding advanced agricultural issues. The use of paper maps may help to improve spatial communication among different participants and integrate the collected 
data with other data sources (Van Wart et al 2010). The farmer should be able to collect spatial information as easily as possible, by taking advantage of his/her knowledge so as to locate the crop variables on a paper map. As experts require information in GIS formats, paper maps need to be introduced in GIS tools to be processed and analyzed. Hence, the mapping process is the vehicle for exchange information. The paper map complements the oral information exchange. Indeed the expert users have an historical record of the field and not just some indications from farmer based on his memory. On the other hand, as the farmers are getting used to this methodology, they will likely read maps easily and will be able to understand the feedback of the expert based on maps.

After our experiment, farmers A, B, C, and D conferred to identify different problems encountered among their parcels and assess next decisions together. Farmers A and B decided to add extra fertilizer to some trees and improved the pruning of a group of trees. Farmer $\mathrm{C}$ will provide more organic matter to some parts of his parcel. Farmer D noticed a draining problem in a group of 11 trees. Farmer D will try to improve drainage in that zone. Farmers B and D will measure their crop yield in the future by terrace instead of by parcel. In summary, most farmers (A, B, C, and D) have made decisions about the field management based on paper maps and expert feedback to improve site-specific farming. Indeed, such decisions were not applied to the entire parcel but focused to particular parts of the parcel (site-specific). Only farmer E did not change his farm management habits.

The principles of site-specific farming (Srinivasan 2006) are reducing costs, optimization of yield and quality in relation to the productivity capacity of each site, improving the management of the resource base, and protecting the environment. A farmer has to be able to gather information about his field in a way that spatial and temporal variation of the field conditions can be recorded and archived. The collected information should be quantitative in order to perform critical analysis and assessment. Nevertheless, qualitative information may also be recorded as the farmer deems useful for crop management. With the input and output records and expert feedback, the farmer can perform site-specific management of the field, according to predefined objective parameters. Such principles mention the need of spatial and temporal data for site-specific management, but they do not focus only on the technology that makes it possible. Therefore, we suggest that, in certain scenarios as those described in this paper, the use of high level technology and equipment is not essential (Cook and Bramley 1998). It is

possible for small holders to take advantage of their field knowledge to locate and represent different variables spatially.

\section{Conclusion}

In this paper we have assessed whether site-specific management may be accomplished based on a low technology dependency (by farmers) and using a participatory GIS approach. The following points are the conclusions of this research:

- The methodology for farmer/user provides useful and easy instructions to follow.

- The handmade maps provide enough information to allow the farmer to understand his crop situation and farm differences.

- GIS outputs provide extra information to allow the farmer to analyze the current situation.

- Site-specific management can be done in small farms based on farmer mental maps, paper maps records, and information exchange with an expert.

- A consultant expert is always needed and can guide the farmer in several tasks such as data collection and decision making. 
- The work-flow provides a dynamic dialogue between the farmer and the expert. Both participants can benefit from this collaborative approach.

Although the farmers already had the required knowledge, only after made the maps were they able to realize the problems affecting particular parts of their parcels and, most importantly, identify the causes that provoked them. Spatial information is of unquestionable value to farmers to make valid decisions. Simple paper maps may be sufficient to incorporate spatial information into the decision-making processes of smallholders. This exercise has provided the farmers with a new tool to collect data and interpret the results obtained to improve the site-specific management of their fields. The expert users can also benefit from papers maps. For instance, if the methodology is adopted by the farmers of a region, the expert users will get an overview of the past and current situation of a given area that may contain several parcels. The participatory methodology provides the expert users first-hand information about the farmers' concern, they receive feedback and added-value information based on the data provided by the farmer. As the spatial information is centralized in a map server, different experts can have access to the data to analyze it and give feedback to other users or to the farmer.

This paper has proposed a methodology to explore the possibilities of involving smallholders in the process of decision making together with experts in a participatory approach using paper maps and geospatial technologies. The proposed methodology may provide a significant change in the adoption of site-specific agriculture: the farmer provides more field data to the expert as long as the expert provides spatial information and useful advice to the farmer. Future plans include testing this methodology on a larger scale. The testing will require the participation of farmer communities, associations or cooperatives initiatives.

\section{References}

Aggelopoulou KD, Wulfsohn D, Fountas S, Gemtos TA, Nanos GD, Blackmore S (2009) Spatial variation in yield and quality in a small apple orchard. Precision Agriculture 11:538-556, 10.1007/s11119-009-9146-9

Altieri MA (2004) Linking ecologists and traditional farmers in the search for sustainable agriculture. Frontiers in Ecology and the Environment 2(1):35-42, 10.1890/15409295(2004)002[0035:LEATFI]2.0.CO;2

Booltink H, van Alphen B, Batchelor W, Paz J, Stoorvogel J, Vargas R (2001) Tools for optimizing management of spatially-variable fields. Agricultural Systems 70(23):445-476, 10.1016/S0308-521X(01)00055-5

Bouma J, Stoorvogel J, Booltink H (1999) Pedology, precision agriculture, and the changing paradigm of agricultural research. Soil Science Society of America Journal (63):1763-1768

Budhathoki NR, Bruce BC, Nedovic-Budic Z (2008) Reconceptualizing the role of the user of spatial data infrastructure. GeoJournal 72(3-4):149-160, DOI 10.1007/s10708-0089189-x

Bugs G, Granell C, Fonts, O, Huerta J, Painho M (2010) An assessment of Public Participation GIS and Web 2.0 technologies in urban planning practice in Canela, Brazil. Cities: The International Journal of Urban Policy and Planning 27(3):172-181, DOI: 10.1016/j.cities.2009.11.008

Cook SE, Bramley RGV (1998) Precision agriculture - opportunities, benefits and pitfalls of site-specific crop management in Australia. Australian Journal of Experimental Agriculture 38(7):753, DOI:10.1071/EA97156

Cook SE, O'Brien R, Corner RJ, Oberthür T (2003) Is precision agriculture irrelevant to developing countries? In: Stafford, J V and Werner, A, Eds, Proceedings of the $4^{\text {th }}$ 
European Conference on Precision Agriculture. Wageningen Academic Publiahers, The Netherlands, pp. 115-119

Diagne A (2009) Technological change in smallholder agriculture: Bridging the adoption gap by understanding its source. In: Agriculture for Development in Sub-Saharan Africa, UC Berkeley: Center of Evaluation for Global Action, Mombasa, Kenya, URL http://www.escholarship.org/uc/item/1wf5q4bm. Last accessed [4/2/2012]

Fountas S, Aggelopoulou K, Bouloulis C, Nanos GD, Wulfsohn D, Gemtos TA, Paraskevopoulos A, Galanis M (2010) Site-specific management in an olive plantation. Precision Agriculture 12(2):179-195, DOI:10.1007/s11119-010-9167-4.

Goodchild MF (2007) Citizens as voluntary sensors: Spatial data infrastructure in the world of web 2.0. International Journal of Spatial Data Infrastructure Research 2:2432

Hall GB, Chipeniuk R, Feick RD, Leahy MG, Deparday V (2010) Community-based production of geographic information using open source software and web 2.0. International Journal of Geographical Information Science 24:761-781, DOI:10.1080/13658810903213288

ITU (2010) Measuring the information society 2010. Tech. rep., International Telecomunication Union, URL http://www.itu.int/ITUD/ict/publications/idi/2010/index.html. Last accessed [4/2/2012]

James J (2008) The digital divide across all citizens of the world: A new concept. Social Indicators Research 89(2):275-282, 10.1007/s11205-007-9156-9

Lamb DW, Frazier P, Adams P (2008) Improving pathways to adoption: Putting the right p's in precision agriculture. Computers and Electronics in Agriculture 61(1):4-9, DOI:10.1016/j.compag.2007.04.009

Ma Y, Chen L, Zhao X, Zheng H, Lü Y (2009) What motivates farmers to participate in sustainable agriculture? evidence and policy implications. International Journal of Sustainable Development \& World Ecology 16(6):374, DOI: $10.1080 / 13504500903319047$

Mann K, Schumann A, Obreza T (2011) Delineating productivity zones in a citrus grove using citrus production, tree growth and temporally stable soil data. Precision Agriculture 12:457-472, DOI: 10.1007/s11119-010-9189-y

MAPA (2003) Libro blanco de la agricultura y el desarrollo rural (Agriculture an rural development white book). Ministerio de Agricultura Pesca y Aalimentación (MAPA), Centro de Publicaciones, Madrid. http://www.libroblancoagricultura.com/publicacion/publicacion.asp. Last accessed [8/2/2012]

Molin J (1997) Agricultura de precisao, parte 1: o que e o estado da arte em sensoriamento (Precision agriculture part 1: remot sensing state of the art). Engenharia Agricola (Brazil) 17(2):97-107. URL http://br.monografias.com/trabalhos901/agriculturaprecisao-sensoriamento/agricultura-precisao-sensoriamento.pdf. Last accessed [9/12/2012]

Nash E, Korduan P, Bill R (2009) Applications of open geospatial web services in precision agriculture: a review. Precision Agriculture 10:546-560

Paar P, Rekittke J (2011) Low-Cost Mapping and Publishing Methods for Landscape Architectural Analysis and Design in Slum-Upgrading Projects . Future Internet 3(4):228-247

Roberts RK, English BC, Larson JA, Cochran RL, Goodman WR, Marra MC, Martin SW, Shurley WD, Reeves JM (2004) Adoption of Site-Specific information and VariableRate technologies in cotton precision farming. Journal of Agricultural and Applied Economics 36(1):148-148 
Sassenrath G, Heilman P, Luschei E, Bennett G, Fitzgerald G, Klesius P, Tracy W, Williford J, Zimba P (2008) Technology, complexity and change in agricultural production systems. Renewable Agriculture and Food Systems 23(Special Issue 04):285-295, DOI: 10.1017/S174217050700213X

Schueller JK (1992) A review and integrating analysis of Spatially-Variable control of crop production. Fertilizer Research 33(1):1-34, 10.1007/BF01058007

Sieber R (2006) Public participation geographic information systems: A literature review and framework. Annals of the Association of American Geographers 96(3):491-507, DOI: $10.1111 /$ j.1467-8306.2006.00702.x

Srinivasan A (2006) Handbook of precision agriculture : principles and applications. Food Products Press, Bringhamton NY

Stoorvogel J (2006) Precision farming and smallholders. URL http://ictupdate.cta.int/en/Regulars/Q-A/Q-A-Precision-farming-and-smallholders. . Last accessed [9/12/2012]

Van Wart S, Tsai KJ, Parikh T (2010) Local ground: a paper-based toolkit for documenting local geo-spatial knowledge. In: [Dearden A.] Proceedings of the First ACM Symposium on Computing for Development, ACM Press, London, United Kigdom, DOI: $10.1145 / 1926180.1926194$ 